\title{
A Case of Neurilemmoma of the Larynx Excised via Trans-Cricothyroid Membrane Approach without Tracheostomy
}

\author{
Dong-Yn Ko, Nam-Hyung Ryou, Jae-Gu Cho, and Jeong-Soo Woo \\ Department of Otorhinolaryngology-Head and Neck Surgery, Korea University College of Medicine, Seoul, Korea
}

\section{기관절개술 없이 윤상갑상막 관통 접근법을 통하여 절제한 후두 신경초종 1예}

고동언 · 류남형 · 조재구 · 우정수

고려대학교 의과대학 이비인후-두경부외과학교실

\author{
Received November 22, 2014 \\ Revised January 9, 2015 \\ Accepted January 9, 2015 \\ Address for correspondence \\ Jae-Gu Cho, MD \\ Department of Otorhinolaryngology- \\ Head and Neck Surgery, Guro Hospital, \\ Korea University College of Medicine, \\ 148 Gurodong-ro, Guro-gu, \\ Seoul 152-703, Korea \\ Tel $+82-2-2626-3189$ \\ Fax $+82-2-868-0475$ \\ E-mail jgcho@korea.ac.kr
}

Neurilemmoma of the head and neck is not rare in parapharynx, but rare in the larynx. The treatment of choice in neurilemmoma of the larynx is a complete surgical resection. A small size lesion can be removed via an endoscopic approach. For a large size lesion, an external approach, such as the median or lateral thyrotomy, or pharyngotomy, can be more useful. These surgical methods often require preliminary tracheostomy to secure the airway. Through a case of neurilemmoma of the larynx, we present this disease and the treatment course of a patient, who has been successfully treated by surgical excision via trans-cricothyroid membrane approach without tracheostomy. Furthermore, we discuss its symptoms, physical examinations, microscopic features and other options of treatment for laryngeal schwannoma through literature reviews. Korean J Otorhinolaryngol-Head Neck Surg 2015;58(6):438-42

Key Words Cricothyroid membrane $\cdot$ Laryngeal neoplasm · Neurilemmoma $\cdot$ Surgery.

\section{서 론}

신경초종의 25 45\%는 두경부에 발생하고 그 중 주로 호 발하는 부위는 부인두 공간이며,2) 후두에서는 드물게 발생 한다. 후두에 발생하는 신경초종은 주로 피열후두개주름과 가성대 부위에 발생하는데 ${ }^{3)}$ 병변이 서서히 자라므로 목안이 꽉 차는 느낌, 목소리 변성이 나타나며 심할 경우 천명과 호 흡곤란이 발생할 수 있다. ${ }^{34)}$ 치료로 내시경적 접근법에서 갑 상연골절개술까지 다양한 수술법이 제시되어 왔다. 애성 및 운동시 발생하는 천명을 주소로 본원에 내원한 환자의 후두 에 발생한 신경초종을 기관 절개술 없이 윤상갑상막을 통해 접근하여 절제한 증례 1 예를 보고하고자 한다.
증 례

39세 남성이 한 달간 지속된 애성을 주소로 본원 이비인후 과에 내원하였다. 환자는 애성 외에도 운동시 흡기성 천명과 호흡곤란이 경미하게 생긴다고 하였다. 20갑년의 흡연력과 20년간의 과도한 음주력 외에 특별한 기왕력은 없었고 과거 8년간 상담직으로 일하며 음성을 남용한 직업력이 있었다. 피부에 커피양 반점 등의 소견은 관찰되지 않았다.

후두내시경상 좌측 진성대가 정중선 쪽으로 밀려있는 소 견이 관찰되었다. 이로 인해 후두가 부분적으로 좁아져 있었 으나 양측 성대는 대칭적으로 잘 움직였다. 성대 내전시 좌 측 가성대 부위가 불룩해졌으나 성대 외전시에는 반대측과 차이가 없었다(Fig. 1).

후두 컴퓨터단층촬영상 좌측 부성문 부위에 둥글고 불균 일하게 조영증강되는 종물이 관찰되었다. 종물은 외측으로 
는 갑상연골과, 후방으로는 피열연골과 접해 있었으며 아래로 는 갑상연골의 하연을 넘어 확장하고 있었으나 주변 연골을 침범하지는 않는 양상이었다. 종양의 크기는 $2.0 \times 2.0 \mathrm{~cm}$ 로 관찰되었다(Fig. 2). 후두 컴퓨터단층촬영 소견을 참고하여 윤상갑상막을 통하여 세침흡인세포검사를 시행하였으나 채 취된 세포량이 부족하여 정확한 진단이 불가능하였다.

기관 절개술을 시행하지 않고 윤상갑상막을 통해 접근하여 좌측 후두 종물을 제거하기로 하였다. 갑상연골의 가운데 부 위 피부에 수평 절개를 가한 후, 흥골설골근을 정중선에서 박 리하고 외측으로 견인하여 윤상갑상막을 찾을 수 있었다. 좌
측의 윤상갑상근을 절개한 후 둥근 낭종의 일부가 갑상연골 하부 경계 바로 아래에서 관찰되었다(Fig. 3). 갑상연골 하연의 일부를 제거하여 낭종을 더 노출시켰다. 낭종을 박리하면서 연 결되어 있는 신경을 관찰할 수 있었으나 신경이 가늘고 여러 갈래로 갈라져 낭종과 박리가 어려워 함께 절제하였다. 내부의 점막은 잘 보존되어 윤상갑상막 절개 부위를 통해 기도의 공기 가 새는 현상은 없었다. 윤상갑상근을 나일론 2-0을 이용하여 갑상연골에 단단히 봉합하였고, 연골막을 포함하여 절개부위 를 층별로 맞추어 닫았다.

환자는 수술 다음 날 퇴원하였으며, 조직검사 결과 $2.0 \times 1.4 \times$
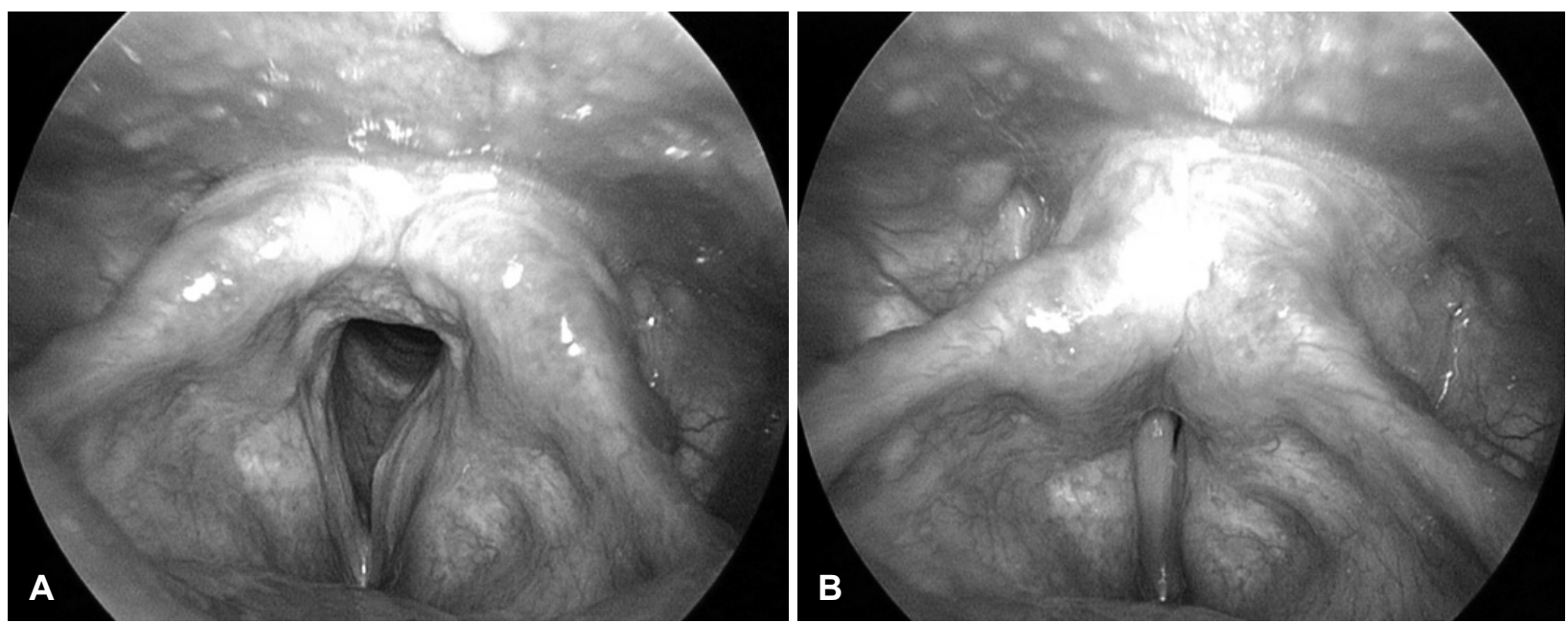

Fig. 1. Preoperative endoscopic laryngeal findings showed a bulging lesion on the left true vocal cord at abduction (A), and a complete closure of the true vocal cords at adduction (B).
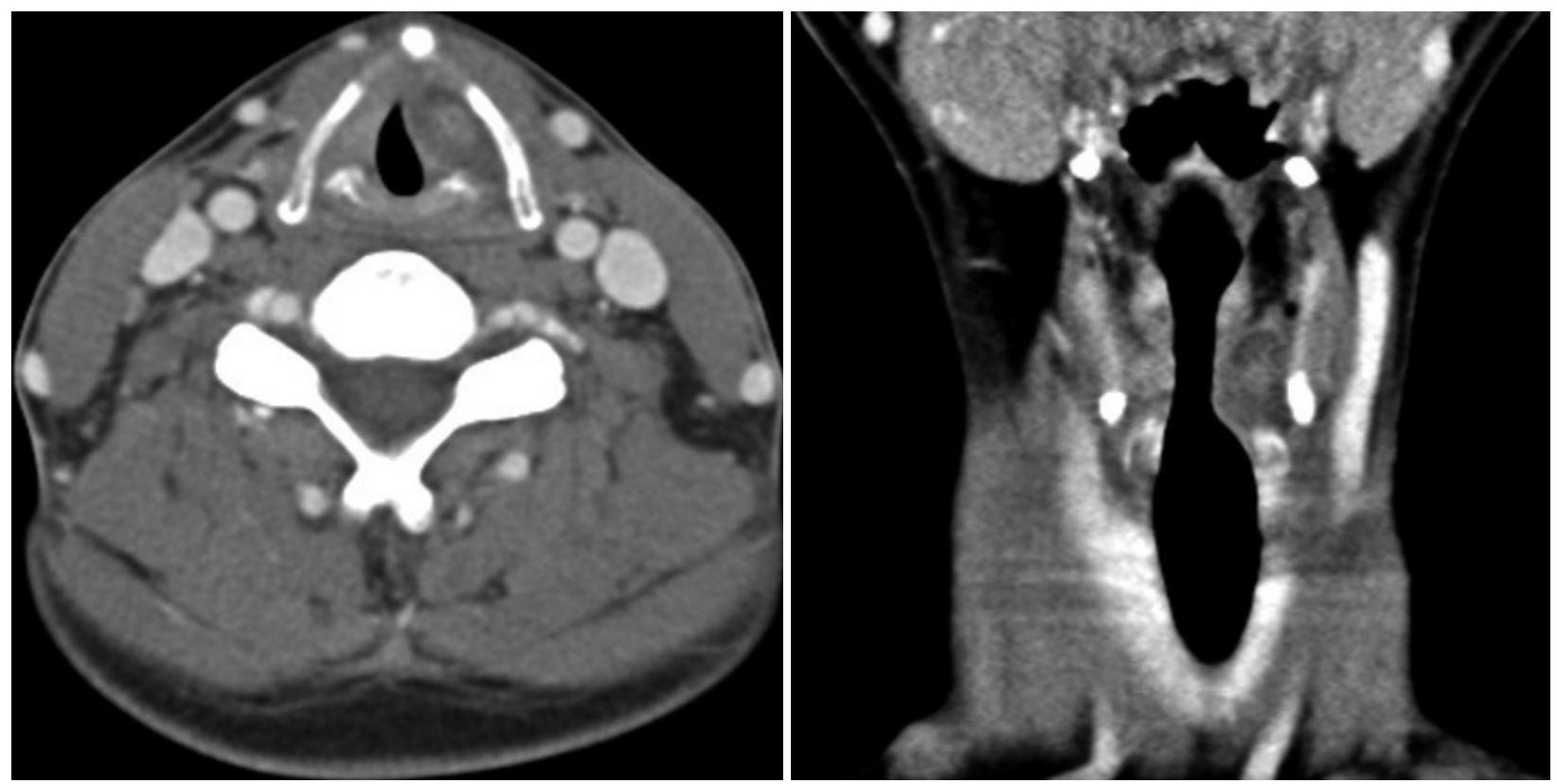

Fig. 2. Preoperative neck CT findings showed about a $2.0 \times 2.0 \mathrm{~cm}$-sized ovoid, well marginated low density mass lesion in the left glottic and subglottic area. The lesion was attached to the left thyroid laterally, and the arytenoid cartilage posteriorly, without a definite sclerosis or erosion. 

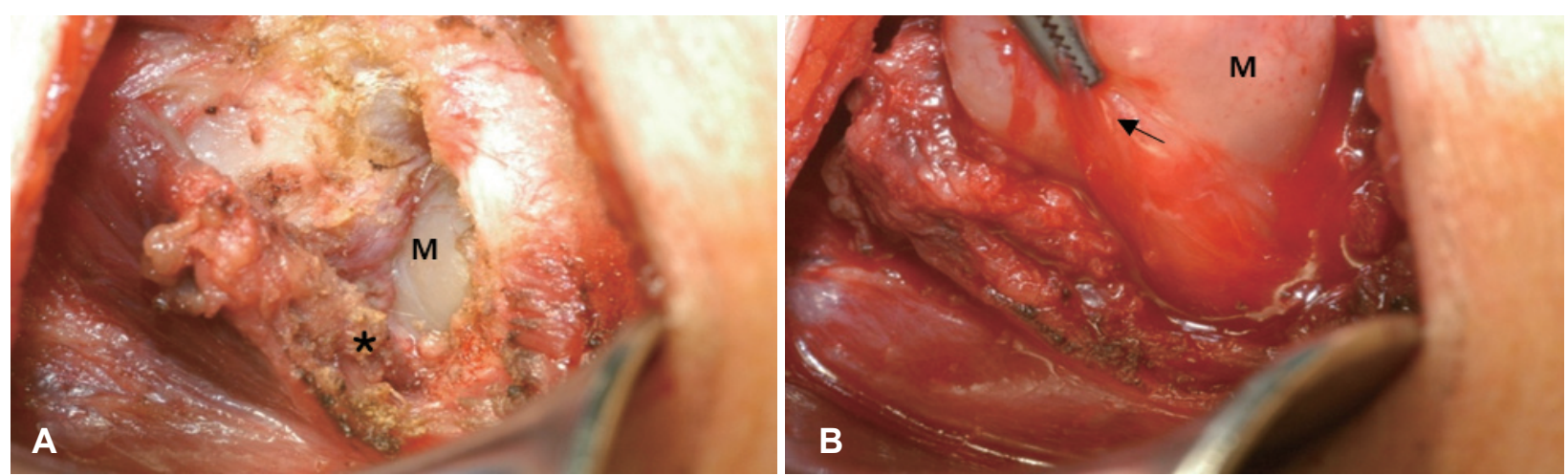

Fig. 3. A part of the thyroid cartilage $(*)$ was removed with Rongeur at the inferior border for a better visualization (A). Then, a well capsulated mass (M) was exposed at the medial aspect to the inferior border of left thyroid cartilage with a suspected nerve origin (arrow) (B).

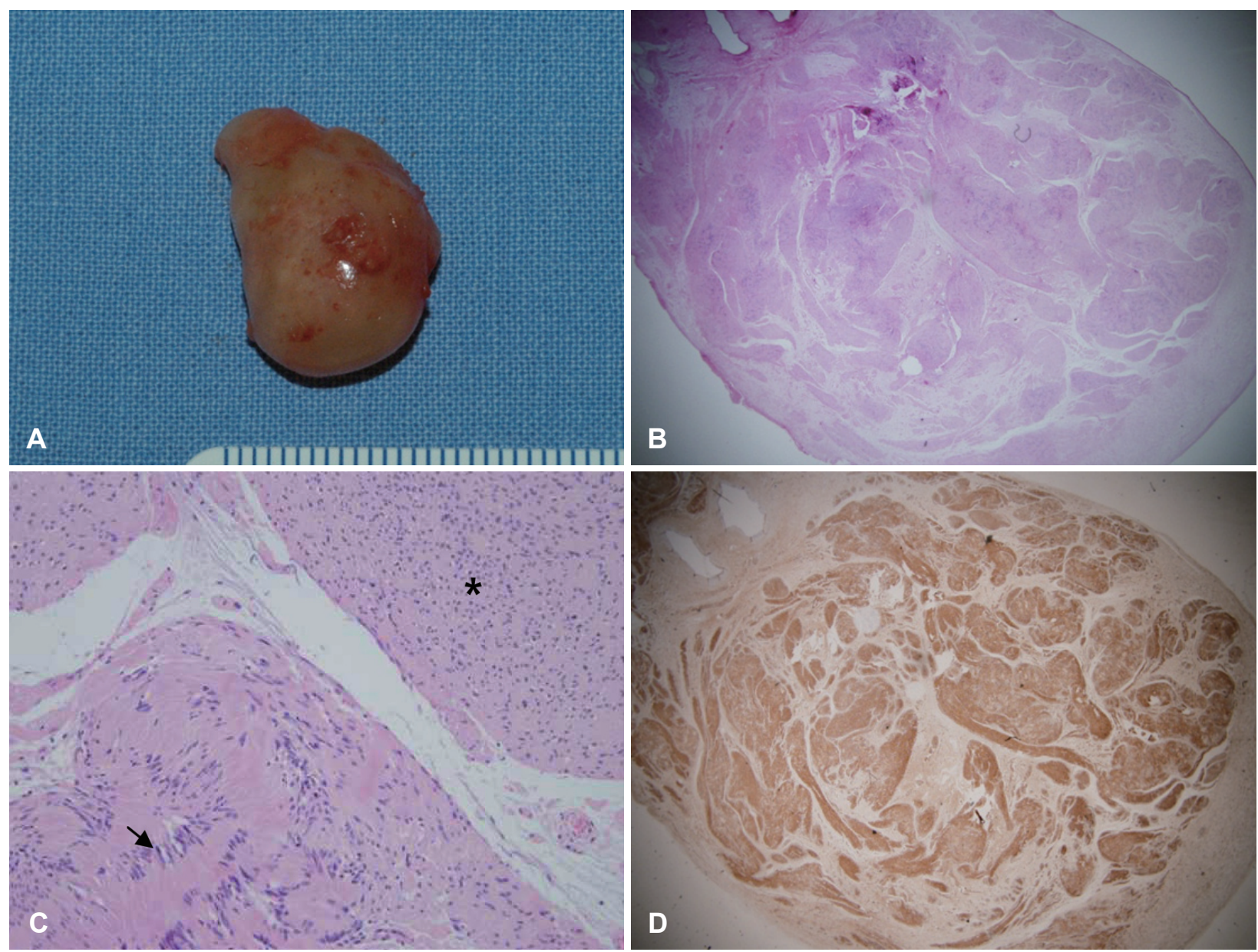

Fig. 4. A $2.0 \times 1.5 \mathrm{~cm}$-sized ovoid mass was excised (A). The definite capsulation was observed in the 10-power field (B), Antoni A (arrow) and Antoni B (*) matrix in the 200-power field (C). S-100 stain showed a positive reaction (D).

$1.0 \mathrm{~cm}$ 크기의 신경초종이었다. 10배율에서 피막을 명확히 관찰할 수 있었으며 200배율에서 Antoni A와 Antoni B 기질 을 확인하였다. S-100 염색에서 양성 소견을 보였다(Fig. 4).

술 후 21일째 환자의 증세는 대체로 호전되었으나 큰 소리 를 내거나 높은 음을 내려고 할 때 약한 소리가 난다고 하였 다. 운동시에 발생하였던 흡기성 천명과 호흡곤란은 더 이상
없다고 하였다. 음성 검사상 Jitter는 수술 전 $1.320 \%$ 에서 수술 후 $0.424 \%$ 로, Shimmer는 수술 전 $7.749 \%$ 에서 수술 후 $4.568 \%$ 로, mean noise-to-harmonics ratio는 수술 전 0.093에서 수 술 후 0.019로 수술 후 호전된 양상을 보였다. 후두내시경 검사 상 좌측 진성대와 성대하부의 점막하 병변이 소실되면서 후두 기도의 폐쇄 양상도 호전되었다. 그러나 좌측 성대의 전후방 

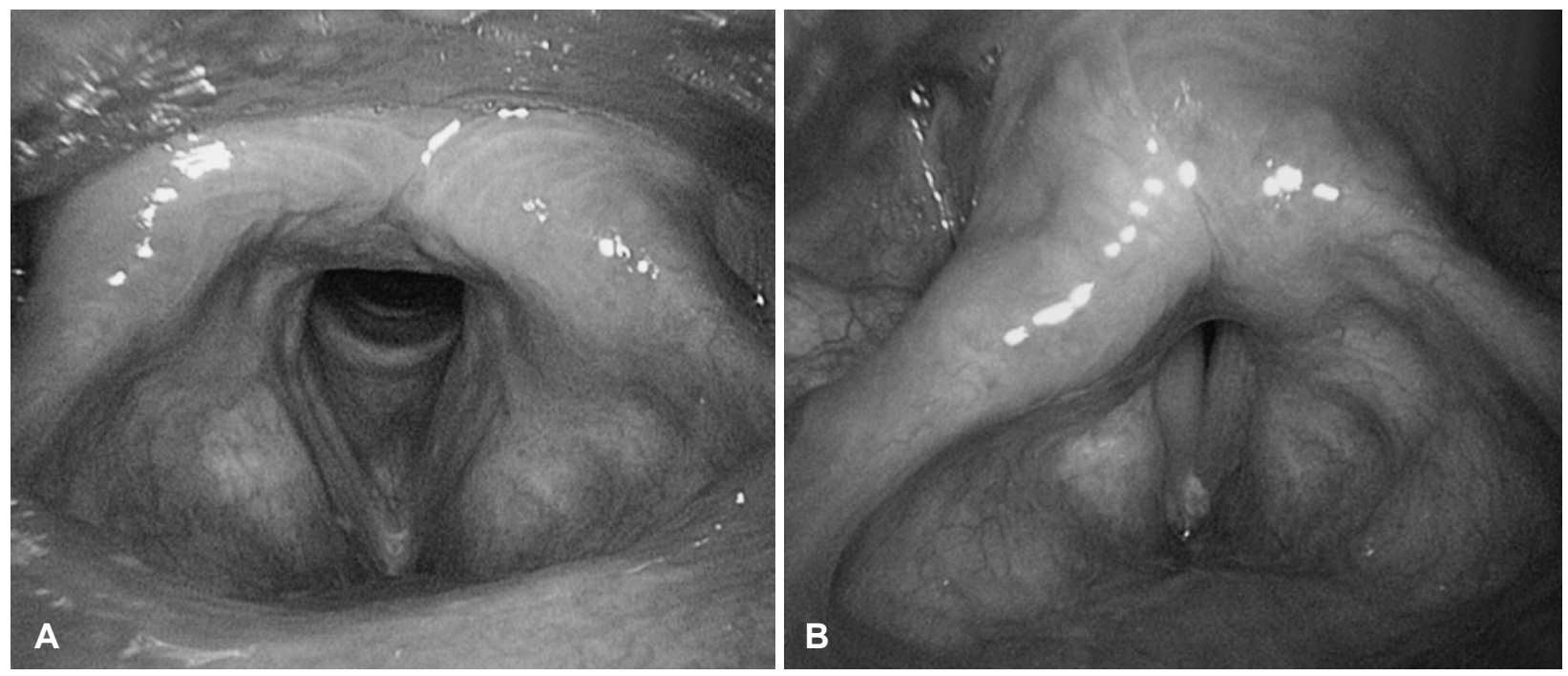

Fig. 5. Postoperative endoscopic examination was done 21 days later from the operation date. The preoperatively observed submucosal lesion in the left vocal cord area was not found postoperatively (A). A posterior glottis chink was observed in the vocal cords adduction, because of weakened tension of the thyroarytenoid muscle of the left vocal cord (B).

장력이 약해져 있어 성문 후방의 틈이 발생하였다(Fig. 5). 환자 는 수술 후 현재까지 음성에 만족하고 있으며 약한 음성이 심해 지거나 좌측 성대의 위축 소견이 보일 경우 성대주입술을 시행 할 예정이다.

\section{고 찰}

후두에 발생하는 신경기원의 양성종양에는 신경초종과 신경 섬유종 두 종류가 있으며 발생률은 매우 낮다. 후두에서 발생 하는 대부분의 신경기원 양성종양은 가성대 부위에 생기며 본 증례와 같이 진성대와 성대 하부에 위치하는 경우는 드물다.

후두내시경 검사상 특징적으로 둥글고 돌출하는 점막하 병 변이 가성대 혹은 피열후두개 주름에서 관찰된다. ${ }^{4)}$ 본 증례에 서는 이러한 돌출 병변이 진성대와 성대 하부에서 관찰되었다.

이 종양은 후두 낭종과 내측 후두류와 감별진단 해야 한다. 경부 전산화단층촬영을 하여 병변의 범위와 주변과의 해부학 적 관계를 파악할 수 있다. 경부 전산화단층촬영에서 후두 신경 초종은 주변을 침범하지 않고 갑상연골 내측을 따라 위치하며 연골 미란이 없고 약하고 비균질적인 조영증강이 특징적으로 관찰된다. ${ }^{6.8}$ 비균질한 조영증강을 알 수 없는 자기공명영상보다 전산화단층촬영이 더 선호된다.) 이러한 소견에 따라 본 증례에 서도 경부 전산화단층촬영 후 드물지만 신경초종의 가능성을 고려할 수 있었다.

후두에 발생한 신경초종은 발생 부위의 특징상 초치료 후 재 발할 경우 호흡곤란 등의 증상이 발생할 수 있고 재수술이 어려 워 재발을 막기 위해 종양을 완전히 절제해야 하며 후두 기능 을 잘 보존할 수 있는 술식을 선택하여야 한다. 종양이 작다면
내시경으로도 제거가 가능하며 $\mathrm{CO}_{2}$ 레이저를 이용하여 재발 없이 잘 치료되었다는 보고가 있다. ${ }^{1)}$ 종양이 크다면 외측 인두 절개술, 내외측 갑상연골절개술 등의 외부 접근을 통해 절제할 수 있다. ${ }^{7}$ 외측 인두절개술은 누공의 형성과 뇌신경 X, XII번 의 손상 가능성 때문에 거의 사용되지 않는다. 2,7) 외측 갑상연 골절개술은 목소리에 악영향을 줄 위험성이 적고 종양을 잘

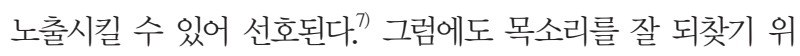
해서는 연골을 다시 정확히 맞추어 복원하여 성대의 레벨을 같 은 높이로 위치시키는 것이 중요하다.

이렇듯 가성대에 발생하고 크기가 큰 신경초종의 수술적 접 근법으로 갑상연골절개술이 선호되지만 가성대에 국한된 신경 초종을 경구강 로봇수술(trans oral robotic surgery)로 완벽 히 제거하였다는 보고도 있다." 종양의 위치에 따라 윤상갑상 막을 통해 접근하는 것이 유리할 수 있다. 가성대에서 성대 하 부에 걸쳐있으며 일부가 후두 바깥으로 확장된, 크기가 큰 신 경초종을 내외측 갑상연골절개술 없이 윤상갑상막을 통해 성 공적으로 절제한 예도 보고된 바 있다. ${ }^{10)}$ 이번 증례의 환자에서 도 종양은 좌측 진성대와 부성대 부위에서 갑상연골 하연 너 머까지 위치하고 있어 종양 노출에는 갑상연골절개술보다는 윤상갑상막을 통해 접근하는 것이 더 유리하리라고 판단하였 다. 갑상연골 하연의 일부를 제거하여 시야를 확보한 후 그 이 상 외측으로의 박리는 피할 수 있었기에 윤상갑상관절을 손 상 없이 보존할 수 있었다.

Zbären과 Markwalder ${ }^{1)}$ 는 신경초종에는 조직학적인 세 가 지 특징이 있다고 하였다. 첫째는 피막이 있고, 둘째, Antoni $\mathrm{A}$ 와 Antoni B 기질이 존재하고, 셋째, S-100 염색에 양성 반 응을 보이는 것이다. Antoni $\mathrm{A}$ 와 Antoni $\mathrm{B}$ 는 신경초종 내의 
기질의 패턴을 설명하는 것으로 Antoni $\mathrm{A}$ (세포성 부위)에서 는 방추세포가 치밀하게 배열되어 그것의 핵이 때로 울타리 모 양을 형성하는 Verocay body를 보인다. ${ }^{5)}$ Antoni $\mathrm{B}$ (부종성 부 위)에서는 방추세포가 느슨하게 배열되고 그 사이에 퇴화, 낭 종 형성, 염증성 변화를 잘 보이는 점액질이 관찰된다.

전체적으로 보면 신경초종은 항상 피막에 둘러싸여 있고 단발성이다. 신경 섬유가 종양이 자라면서 종양의 표면 위를 덮 기 때문에 이론적으로 수술시 신경을 박리하는 것이 가능하다. 또한 피막이 있어 완전 절제가 가능하다. ${ }^{5)}$ 반대로 신경섬유종 은 피막으로 싸여있지 않고 대개 다발성이다. 수술시 종양에 서 신경을 박리하는 것은 거의 불가능하다.5)

후두에 발생하는 신경초종은 드문, 양성 신경기원 종양으로 본 증례는 진성대와 성대 하부에 발생한, 점막하에 팽창된 병 변의 전형적인 모습을 보여주고 있다. 기관절개술을 시행하지 않고 윤상갑상막을 통해 접근하여 병변을 기원 신경 일부와 함께 완전히 절제하였으며 수술 후 새롭게 발생한 좌측 성대의 전후방 장력의 약화는 종양이 상후두 신경의 내측 분지가 아 닌, 반회후두신경에서 기원했음을 추정할 수 있게 한다. 또한 술 후 환자가 높은 음을 낼 때 약하게 소리 나는 점이 윤상갑상근 의 절개 때문일 가능성도 있으나 성대의 움직임으로 보아 갑상 피열근의 부분적 마비로 인한 가능성이 더 높다고 판단된다.

후두의 신경초종은 크기와 위치에 따라 수술시 접근법을 다
르게 선택할 필요가 있으며 기관절개술 없이도 치료가 가능하 리라 생각된다. 기원하는 신경 역시 신경초종의 발생 부위에 따라 다를 수 있음을 염두에 두어야 한다.

\section{REFERENCES}

1) Zbären $P$, Markwalder R. Schwannoma of the true vocal cord. Otolaryngol Head Neck Surg 1999;121(6):837-9.

2) Sanghvi V, Lala M, Borges A, Rodrigues G, Pathak KA, Parikh D. Lateral thyrotomy for neurilemmoma of the larynx. J Laryngol Otol 1999;113(4):346-8.

3) Bastian RW. Benign Vocal Fold Mucosal Disorders. In: Flint PW, Haughey BH, Lund VJ, Niparko JK, Richardson MA, Robbins KT, et al., editors. Cummings Otolaryngology Head \& Neck Surgery. 5th ed. Philadelphia, PA: Mosby Elsevier;2010. p.882.

4) Rosen FS, Pou AM, Quinn FB Jr. Obstructive supraglottic schwannoma: a case report and review of the literature. Laryngoscope 2002;112 (6):997-1002.

5) Jones SR, Myers EN, Barnes L. Benign neoplasms of the larynx. Otolaryngol Clin North Am 1984;17(1):151-78.

6) Cadoni G, Bucci G, Corina L, Scarano E, Almadori G. Schwannoma of the larynx presenting with difficult swallowing. Otolaryngol Head Neck Surg 2000;122(5):773-4.

7) Cummings CW, Montgomery WW, Balogh K Jr. Neurogenic tumors of the larynx. Ann Otol Rhinol Laryngol 1969;78(1):76-95.

8) Newman D, Youngs R. Neurilemmoma of the larynx. J Otolaryngol 1992;21(1):72-3

9) Kayhan FT, Kaya KH, Yilmazbayhan ED. Transoral robotic approach for schwannoma of the larynx. J Craniofac Surg 2011;22(3):1000-2.

10) Ishida Ueha $R$, Nishimura $S$, Nito $T$. Laryngeal schwannoma with extralaryngeal extension. Auris Nasus Larynx 2012;39(3):317-20. 